\title{
A revista Arquitetura e Urbanismo do IAB: metropolização e modernização no Brasil dos anos 1930
}

\author{
André Cruz Rodrigues*
}

Resumo O artigo observa a cultura arquitetônica moderna no Brasil através da revista Arquitetura e Urbanismo, órgão oficial do IAB Instituto de Arquitetos do Brasil, tomando como recorte específico o período de circulação do periódico, que vai de 1936 a 1942. Após situar a revista enquanto objeto cultural e meio de comunicação especializado produzido por arquitetos para arquitetos, a discussão avança, utilizando-se dos conceitos de metropolização e modernização como suporte argumentativo para a análise de algumas arquiteturas publicadas pela revista do IAB cuja modernidade implícita ainda não encontrou espaço nas narrativas bem delineadas dos manuais de história da arquitetura.

Palavras-chave: arquitetura na década de 1930, Instituto de Arquitetos do Brasil (IAB), revistas de arquitetura.

\section{La revista Arquitetura e Urbanismo del IAB: metropolización y modernización en Brasil de los años 1930}

\begin{abstract}
Resumen El artículo observa la cultura arquitectónica moderna en Brasil a través de la revista Arquitetura e Urbanismo, órgano oficial del IAB Instituto de Arquitetos do Brasil, tomando como recorte específico el período de circulación del periódico, que va de 1936 a 1942. Después de situar la revista como objeto cultural y medio de comunicación especializada producido por arquitectos para arquitectos, la discusión avanza, utilizándose de los conceptos de metropolización y modernización como soporte argumentativo para el análisis de algunas arquitecturas publicadas por la revista del IAB cuya modernidad implícita aún no encontró espacio en las narrativas bien delineadas de los manuales de historia de la arquitectura.
\end{abstract}

Palabras clave: arquitectura en la década de 1930, Instituto de Arquitetos do Brasil (IAB), revistas de arquitectura.

\section{The magazine Arquitetura e Urbanismo of the IAB: metropolization and modernization in Brazil of the 1930s}

\begin{abstract}
The article observes the modern architectural culture in Brazil through the magazine Arquitetura e Urbanismo, official organ of the IAB Instituto de Arquitetos do Brasil, taking as a specific cut the circulation period of the periodical, that goes from 1936 to 1942 . After situating the magazine as object cultural and specialized means of communication produced by architects for architects, the discussion advances, using the concepts of metropolization and modernization as an argumentative support for the analysis of some architectures published by the magazine of the IAB whose implicit modernity has not yet found space in well-delineated narratives of architecture history manuals.
\end{abstract}

Keywords: architecture in the 1930's, Instituto de Arquitetos do Brasil (IAB), architecture magazines. 
intervalo situado entre o impacto do modernismo dos anos 1920 e a tendência de síntese e universalização das experiências de vanguarda no imediato pós-guerra é caracterizado pela coexistência entre impulsos de ruptura com a tradição e resistências acadêmicas, o que se dá no interior de uma cultura onde há um pleno sentimento de pertencimento à modernidade por parte dos arquitetos ${ }^{1}$. No Brasil, esse espírito é bem representado por um periódico pouco conhecido e estudado, a revista Arquitetura e Urbanismo, publicada como órgão oficial do Instituto de Arquitetos do Brasil (IAB) entre 1936 e 1942, aqui adotada como fonte de pesquisa para se discutir através de algumas obras, uma arquitetura cuja modernidade 2 implícita ainda não encontrou espaço nas narrativas bem delineadas dos manuais de história da arquitetura.

\section{A primeira revista produzida por arquitetos para arquitetos}

Porta-voz e autointitulada "Órgão Oficial do Instituto de Arquitetos do Brasil", a revista bimestral Arquitetura e Urbanismo teve a primeira edição publicada em maio de 1936 e a última em maio de 1942. Com temática centrada na defesa e na divulgação da profissão regulamentada em 1933, Arquitetura e Urbanismo pode ser considerada a primeira revista especializada em arquitetura do Brasil produzida exclusivamente por arquitetos para arquitetos como classe reconhecida por lei ${ }^{3}$.

O periódico teve como idealizador e primeiro diretor Cipriano Lemos, engenheiroarquiteto positivista e um dos fundadores do IAB. Formado pela Escola Nacional de Belas Artes nos anos 1920, Ricardo Antunes foi redator-chefe de urbanismo e diretor da revista após o falecimento de Cipriano Lemos em 1939. Gerson Pompeu Pinheiro, aluno e defensor da reforma da ENBA, terceiro lugar no concurso do MESP, que depois adota um tom crítico ao grupo de Lucio Costa foi redator-chefe de arquitetura. O imigrante húngaro Adalbert Szilard, o presidente do IAB Augusto de Vasconcellos Júnior e Paulo Pires, professor da ENBA e sócio de Paulo Santos no próspero e longevo escritório Pires \& Santos fizeram parte do conselho técnico da revista.

O posicionamento inicial eclético ${ }^{4}$ e pragmático de Arquitetura e Urbanismo é demarcado por Cipriano Lemos ao utilizar como pano de fundo a publicação de uma matéria tardia sobre o Copacabana Palace:

Deveríamos ter dito no artigo INAUGURAL, com que apresentámos ao público esta revista, que a nossa bandeira é o ecletismo. [...] Quando a discórdia moral e intelec-

* André Cruz Rodrigues é Arquiteto e Urbanista, mestrando em Teoria e História da Arquitetura e do Urbanismo pelo Instituto de Arquitetura e Urbanismo da Universidade de São Paulo - IAU USP, ORCID <http://orcid.org/00000002-6430-093X> tual minorar; quando as aperturas econômicas do mundo diminuírem; quando cessarem a corrida armamentista e a exacerbação nacionalista, então, o arquiteto voltará a ser o grande artista da sociedade, como sempre foi em saudosas épocas. Mas até lá tudo é incerto e quiçá transitório. Algumas revistas como L'ARCHITECTURE D'AUJOURD'HUI se consagram a estampar a arquitetura do dia. Entretanto muitas outras publicam de tudo. Nós adotámos este critério, não somente pelo espírito de 
1 Quanto ao conceito de moderno que os arquitetos brasileiros faziam de si mesmos e dos seus colegas nos anos 1930, Carlos Martins esclarece: "Acreditar que, por se dar em torno da ideia de novo, o embate estava previamente assegurado aos modernistas é incorrer no anacronismo de supor que Memória, ou o próprio Piacentini, se apresentassem ou fossem imediatamente identificáveis ao retrocesso. Capanema, já o vimos, considerava Piacentini um arquiteto moderno" (MARTINS, 1987, p. 169).

2 A difícil conceituação do moderno em arquitetura nos leva a adotar aquela que pensamos ser a mais adequada e sensata produzida até o momento. Sarah Goldhagen (2008), após demonstrar ser insustentável o entendimento da arquitetura moderna como estilo, define o modernismo em arquitetura de modo abrangente e inclusivo: "un discurso centrado en el problema de cómo el ambiente construido deberia imbricarse y responder al complejo fenómeno de la modernidad [...] el modernismo en arquitectura consiste en un conjunto de discusiones y debates cohesionados alrededor de un conjunto de proposiciones y una pluralidad de respuestas que difieren en los fines buscados y en la arquitectura propuesta y construida, incluidas sus inclinaciones estilísticas" (GOLDHAGEN, 2008, p. 36).

3 A revista Architectura do Brasil publicada entre 1921 e 1926 (RABELO, 2011, p. 138), pode ser considerada uma precursora do periódico em questão, em primeiro lugar por haver uma continuidade em parte dos arquitetos envolvidos nas duas publicações e principalmente pelo fato da revista dos anos 1920 se considerar a voz do Instituto Brasileiros de Arquitetos, primeira associação de classe que mais tarde se tornaria o IAB.

4 Cipriano Lemos se utiliza do termo "ecletismo" no seu sentido filosófico não no estilístico

5 Entre os arquitetos consagrados pela historiografia que circulam no periódico desde o seu início, estão Marcelo e Milton Roberto e Attílio Corrêa Lima. A partir de

.. continua na página 5 ... relatividade acima apontado, como tambem porque o nosso meio, ainda insuficiente, não permite que um periódico deste gênero se dê ao luxo de exclusivismos doutrinários. O que procuramos fazer é selecionar a matéria. Se conseguirmos publicar bons trabalhos, tão somente teremos feito o bastante. (ARQUITETURA E URBANISMO, n. 2, p. 8-9, jul./ago., 1936)

Ao buscar situar o lugar da revista do IAB na cultura arquitetônica dos anos 1930, Clévio Rabelo observou que ao longo dos anos "a revista se aproximou das realizações do grupo de Lúcio Costa" (RABELO, 2011, p. 143). Seguindo a mesma linha, Juliana Nery (2013), sustenta que após o falecimento inesperado de Cipriano Lemos e a ascensão de Ricardo Antunes à diretoria, o periódico passa a ter uma maior abertura para a arquitetura moderna de matriz corbusiana.

Quanto a esse aspecto, cabe ressaltar, que a vertente dita "modernista", ou aquela derivada das vanguardas dos anos 1920, conforme o termo corrente utilizado na época pela revista, sempre encontrou espaço no periódico, cuja característica principal foi o debate intenso, o que se dava principalmente através dos artigos publicados que tratavam basicamente de discutir os diversos caminhos e possibilidades da arquitetura diante do intenso processo de modernização posto em curso por Getúlio Vargas.

Apesar da suposta abertura oferecida por Ricardo Antunes à arquitetura daqueles que na década seguinte viriam a consolidar o paradigma da arquitetura moderna brasileira ${ }^{5}$, não é possível vincular Arquitetura e Urbanismo a uma imagem de precursora do chamado modernismo brasileiro que se afirmaria a partir do pós-guerra, pois, a postura eclética e mesmo desconfiada com relação aos diversos discursos e posicionamentos modernos permaneceu até o fim da publicação em 1942. A leitura de algumas capas publicadas pela revista do IAB, longe de esgotar a discussão, ilustra e nos serve como ponto de partida para questionar as tentativas de detectar suas tendências.

Independentemente das pressões da realidade impostas à tarefa de se produzir um periódico especializado em arquitetura que também se coloca como empreendimento comercial, tal discussão acerca do posicionamento da revista diante do debate moderno procura enfatizar, em primeiro lugar, a complexidade da cultura arquitetônica dos anos 1930, além de atentar para uma tendência teleológica da historiografia de relacionar um tanto apressadamente tudo aquilo que vem antes ou depois do momento de consolidação da arquitetura moderna brasileira ${ }^{6}$ com o próprio fato.

De início voltada quase exclusivamente para o contexto carioca, onde o arquiteto escocês imigrado Robert Prentice se destaca pelo maior número de projetos publicados, Arquitetura e Urbanismo passa a oferecer uma maior abertura para outras regiões do Brasil, principalmente para São Paulo, a partir de 1940. É curioso observar que a revista encerrou as atividades no final de 1942 e que logo no ano seguinte o IAB inaugurou os escritórios de São Paulo e Belo Horizonte, o que denota uma diminuição do poder de fala emanado da capital federal e a emergência de centros rivais. Além disso, ainda em 1943, foi colocada em prática a proposta de eleger um presidente do $I A B$ de fora do grupo dos sócios fundadores ${ }^{7}$ de 1921, visando uma abertura para os "grandes nomes da arquitetura brasileira" (PINHEIRO, 2001, p. 39), cujo eleito foi Paulo de Camargo e Almeida. Apesar das conjecturas que indicam uma incompatibilidade daquele modelo de publicação com a mudança de ares dos anos 1940, não foram encontrados registros que confirmem ser essa uma hipótese verdadeira. 
A revista Arquitetura e Urbanismo do IAB: metropolização e modernização no Brasil dos anos 1930 | 4
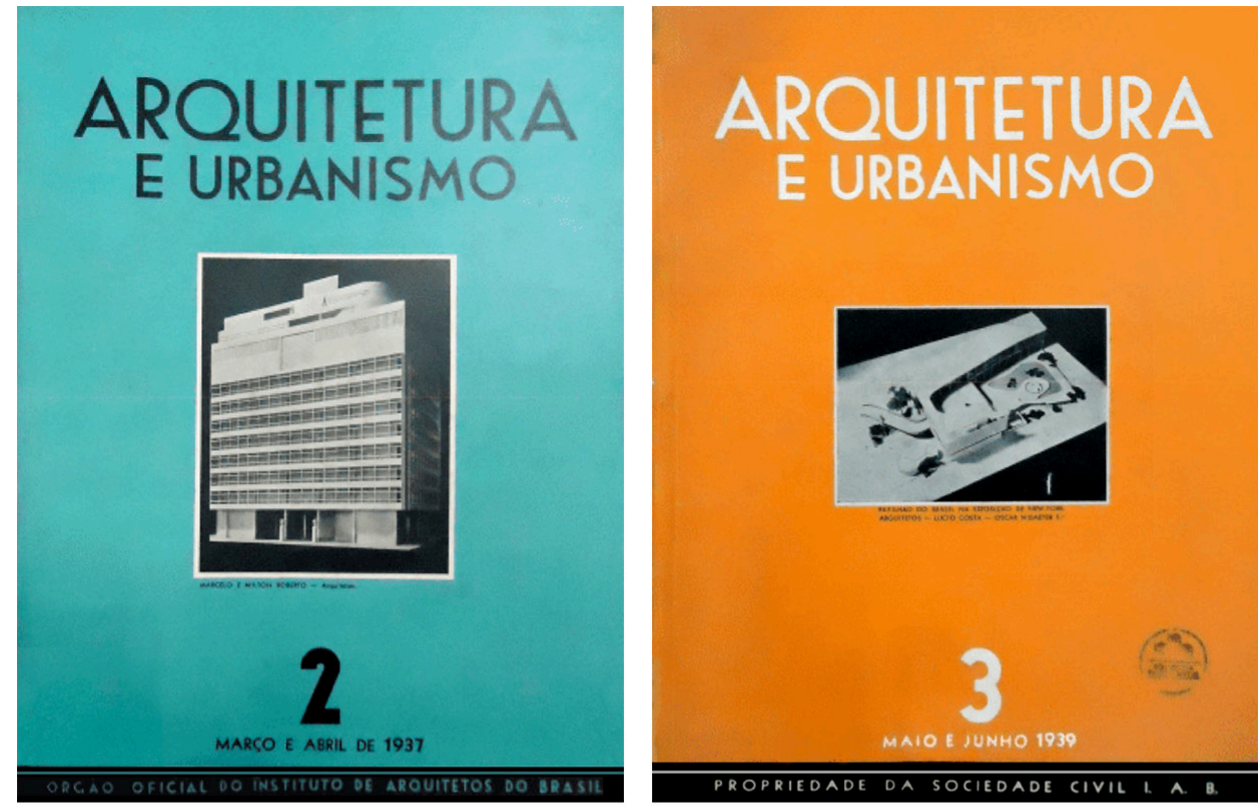

\section{AROUITETURA E URBANISMO}

ARQUITETURA E URBANISMO

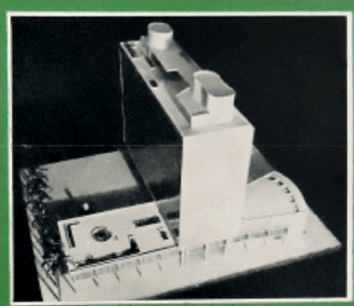

$$
4
$$

JULO E AGOSTO 1939

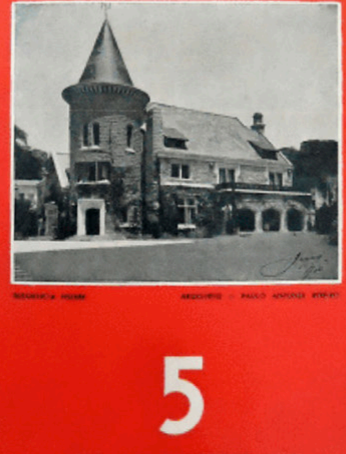

SETEMBRO E OUTUBRO 1939 
... continuação da nota 5 ...

1939 foram publicados projetos de Lucio Costa (fase modernista) e Oscar Niemeyer. Nota-se que o editorial da revista não imprime qualquer sentido de excepcionalidade às obras publicadas que em breve seriam consideradas seminais.

6 Aquele que foi considerado mais expressivamente pela historiografia, mais especificamente, a construção do edifício do Ministério da Educação e Saúde Pública.

7 Segundo o Boletim nº 1 do Instituto de Arquitetos do Brasil, em 1921 vinte e sete arquitetos lançaram as bases da primeira associação de classe o "Instituto Brasileiro de Arquitetos", devido a uma discordância relativa a um concurso, ocorreu uma cisão do grupo, surgindo a "Sociedade Central de Arquitetos", no entanto, em 1924 as duas associações se fundiram novamente recebendo a denominação "Instituto Central de Arquitetos" (ARQUITETURA E URBANISMO, n. 2, maio/ jun., 1936). Em 1934 o instituto recebeu sua denominação definitiva "Instituto de Arquitetos do Brasil" (PINHEIRO, 2001).

8 Segundo o Censo do IBGE de 1940, a população presente na cidade do Rio de Janeiro era de 1.764.141 pessoas (IBGE, 2018).

\section{Metropolização e modernização}

Sujeito a resignificações por se referir às cidades como objetos em transformação, o conceito de metropolização tem sido debatido por geógrafos e urbanistas, resultando em uma série de definições sem que qualquer uma delas se sobressaia. Entre essas conceituações, aquela que melhor se enquadra no escopo do presente artigo, na função de suporte argumentativo, foi desenvolvida por Regina Meyer:

"Historicamente, a metrópole moderna esteve profundamente associada a processos de industrialização e urbanização aceleradas. O espaço físico resultante desses dois processos identificou-se, por sua vez, com pelo menos três características básicas: congrega enormes populações; é multifuncional; e, possui relações econômicas diferenciadas tanto no âmbito nacional como no internacional. Nesse sentido, a metropolização é descrita como o aprofundamento contínuo dessas características essenciais". (MEYER, 2004, p. 20)

Não menos labiríntico em termos semânticos, o conceito de modernização aqui empregado, se refere estritamente ao contexto histórico do Brasil nos anos 1930, tendo como pano de fundo a análise de Boris Fausto (1995) sobre o quadro de modernização conservadora implementado pelo estado getulista entre 1930 e 1945. A síntese desse panorama trazido por Fausto que norteia este estudo, pode ser definida como uma transição do Brasil agrário e rural para o Brasil urbano e industrial, por meio da adoção de uma política econômica de cunho nacionalista e estatizante.

Partindo desse contexto, convém iniciar a análise das obras publicadas em Arquitetura e Urbanismo através dos edifícios e salas de cinema, pois, estes representam muito bem o panorama cultural e urbanístico da primeira metade do século 20, principalmente se forem pensados como definidores do uso do espaço público como lugares de sociabilidade, constituindo verdadeiras ilhas de entretenimento nas emergentes metrópoles brasileiras. Ao escrever sobre a arquitetura de cinemas em São Paulo, Renato Anelli observa:

Portador de imagens da vida nas grandes metrópoles norte-americanas e europeias, o cinema serve de referência de urbanidade para grandes contingentes de especta dores. Por ser uma linguagem essencialmente moderna, contribui para construir uma nova relação entre seu público e o cotidiano da vida urbana, tematizando a velocidade e fragmentação da vida moderna, interferindo em seus hábitos culturais e sociais. (ANELLI, 1992, p. 263)

Apesar da revista também ter publicado o Cine Ipanema (1936), o Cine Roxy (1939) e o Cine Metro Tijuca (1942), estas edificações se enquadram melhor em um contexto de bairro. Já no caso do Cine Metro do Rio de Janeiro, construído em 1936, conhecido como Cine Metro Passeio, a escala é decididamente metropolitana ${ }^{8}$. Projeto do arquiteto escocês radicado no Rio de Janeiro Robert Prentice, esse híbrido de cinema e edifício de escritórios, hoje reconhecível apenas através de sua volumetria, chama a atenção pelo gigantismo da sala de exibição e pelo acabamento luxuoso dos interiores, o que mostra a relevância alcançada por esse tipo de entretenimento na época. A importância da ornamentação se faz notar consumida como signo de distinção social e manutenção do decoro no interior da cultura dos anos 1930, no 
Figura 2: Cine Metro Rio de Janeiro. Fonte: ARQUITETURA E URBANISMO, 1936, n. 4, p. 184

Figura 3: Cine Metro Rio de Janeiro. Fonte: ARQUITETURA E URBANISMO, 1936, n. 4, p. 199. entanto, essas características de permanências da tradição, receberam um tratamento modernizado nas fachadas, ao incorporar a tendência de simplificação geométrica das vanguardas europeias, através da via que ficou conhecida posteriormente como art déco, uma das alternativas mais utilizadas na época para ser e expressar o desejo de ser moderno.
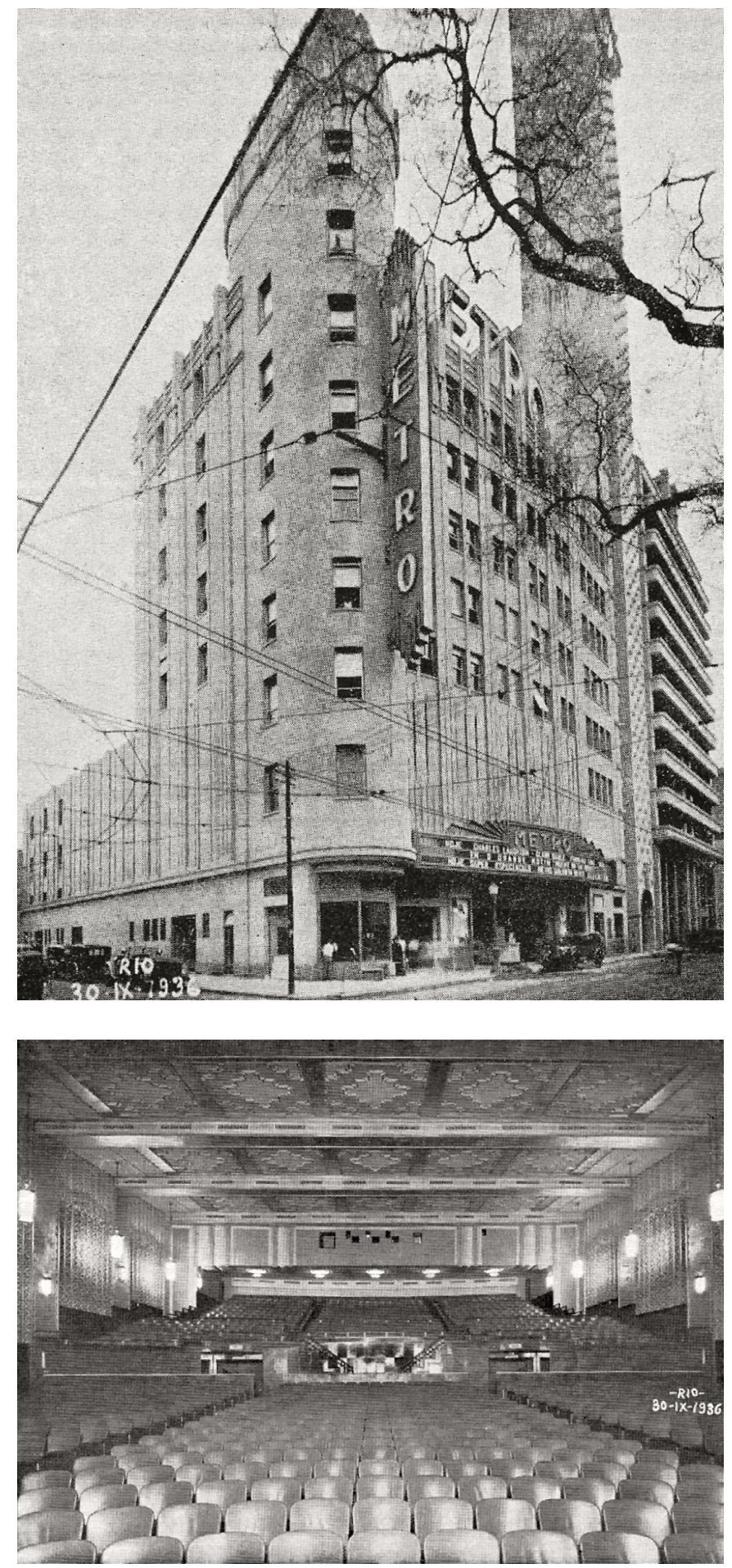
9 A recém lançada revista Acrópole também publicou no seu primeiro número uma matéria continua na página 8 ...

Figura 4: Cine Metro São Paulo. Fonte: ARQUITETURA E URBANISMO, 1938, n. 3, p. 141

Figura 5: Cine Metro São Paulo. Fonte: ARQUITETURA E URBANISMO, 1938, n. 3, p. 144
Projeto do mesmo arquiteto, também para a MGM, o Cinema Metro de São Paulo ${ }^{9}$ foi inaugurado em 1938, naquela que já podia ser considerada a segunda metrópole brasileira a contabilizar mais de um milhão de habitantes ${ }^{10}$. O prédio ainda existente, hoje sede de uma igreja, recebeu o mesmo padrão de acabamento luxuoso da versão carioca, porém, a escala é menor. Quanto a esse aspecto, cabe observar que o Cine Metro Rio foi concebido como um edifício de múltiplo uso de fato, enquanto que o Cine Metro São Paulo trata-se de um edifício-cinema cuja fachada simula um prédio comercial ou residencial de uma grande cidade.
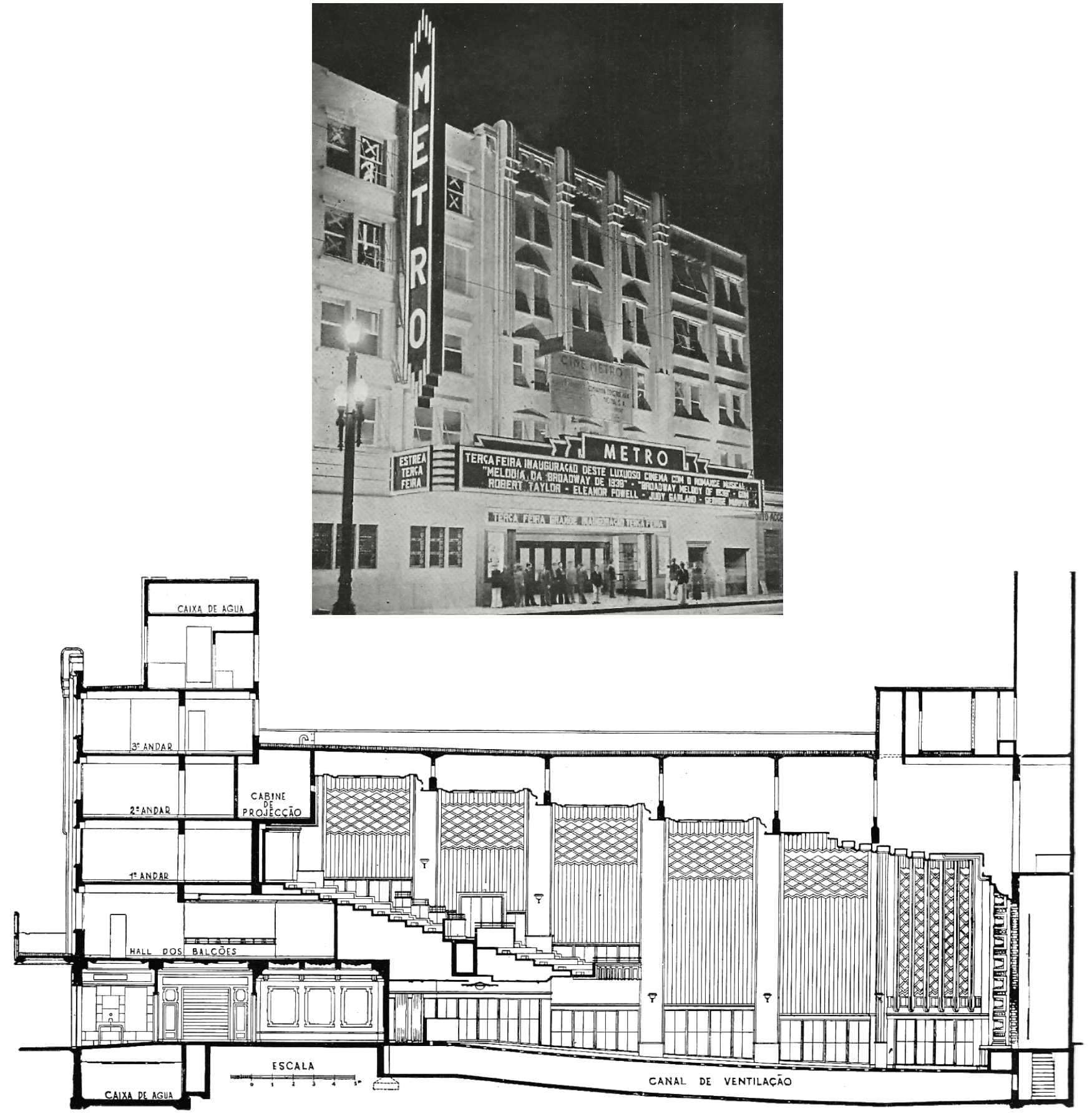
... continuação da nota 9 ...

sobre o edifício, o curioso é que na revista paulista não é citada a autoria da obra apenas a construtora (ACRÓPOLE, n. 1, mai., 1938, p. 44).

10 Segundo o Censo do IBGE de 1940, a população presente na cidade de São Paulo era de 1.326.261 pessoas (IBGE, 2018).
No edifício carioca o programa do cinema se desenvolve integralmente no embasamento, para a partir dessa base receber mais cinco andares destinados a escritórios. Já no caso paulistano, todo o corpo do edifício atende à função de cinema e apesar da fachada denotar outros usos, sua real utilidade é abrigar a cabine de projeção e as demais salas técnicas e operacionais. Tal leitura elucida que no processo de metropolização-modernização, para além do predomínio da esfera material na produção do espaço, a instância simbólica entra como elemento definidor indispensável do processo.

É interessante ressaltar como característica marcante de ambos os edifícios, que a parafernália de comunicação visual que conforma através da luz artificial e da forma a paisagem urbana das cinelândias brasileiras, ganha força simbólica ao se tornar um quase ícone de metrópole da primeira metade do século XX. Nesse caso, o fenômeno se intensifica ao afirmar o padrão de design aplicado em escala global pela marca Metro Goldwyn Mayer, que não por acaso, ostenta o prefixo "METRO" em letras garrafais.

Se o processo de metropolização e modernização trouxeram como consequência inevitável a verticalização do espaço construído nas duas principais capitais brasileiras na época, cabe abordar como representante daquele que talvez seja o programa moderno per se, a publicação dos edifícios comerciais conjugados Castello, Nilomex e Raldia, também projeto de Prentice, construídos em 1937 no centro do Rio de Janeiro.

Sem recuos, com pátio interno, que no projeto original incluía a circulação pública de pedestres, o conjunto serpenteia três faces de uma quadra, no térreo há uma grande lógia abrigando o comércio, o que resulta na interessante relação de compartilhamento entre espaço público-privado e na demarcação monumental da base do edifício.

O corpo do prédio comporta as salas comerciais, algumas delas ocupadas pelos escritórios de arquitetos proeminentes na época, como Angelo Murgel, Attílio Corrêa Lima e o próprio Prentice. No coroamento há uma platibanda com os ornamentos déco, de influência mesoamericana, padronizados e aplicados quase que em escala industrial em praticamente todos os edifícios projetados por Prentice e sua equipe. Desfigurado no seu projeto original ao sofrer uma adição de andares e pela construção dos volumes na cobertura, foi quase demolido nos anos 1990 . Em 2008 o conjunto passou por um retrofit onde teve o seu interior remodelado e ocupado pela Petrobrás, mantendo inalteradas as fachadas tombadas pelo patrimônio histórico (ROITER, 2008).

Essa proposta de edifícios conjugados com distinção administrativa, mas que fazem parte de uma grande massa arquitetônica, poderia ser pensada como precursora de edifícios modernistas consagrados como o Conjunto Nacional em São Paulo. Teríamos duas soluções de projeto muito próximas ao imaginar o edifício erguido nos anos 1930, com uma maior permeabilidade de pedestres no térreo e com as salas comerciais condensadas em uma lâmina de vários andares destacada do alinhamento. 


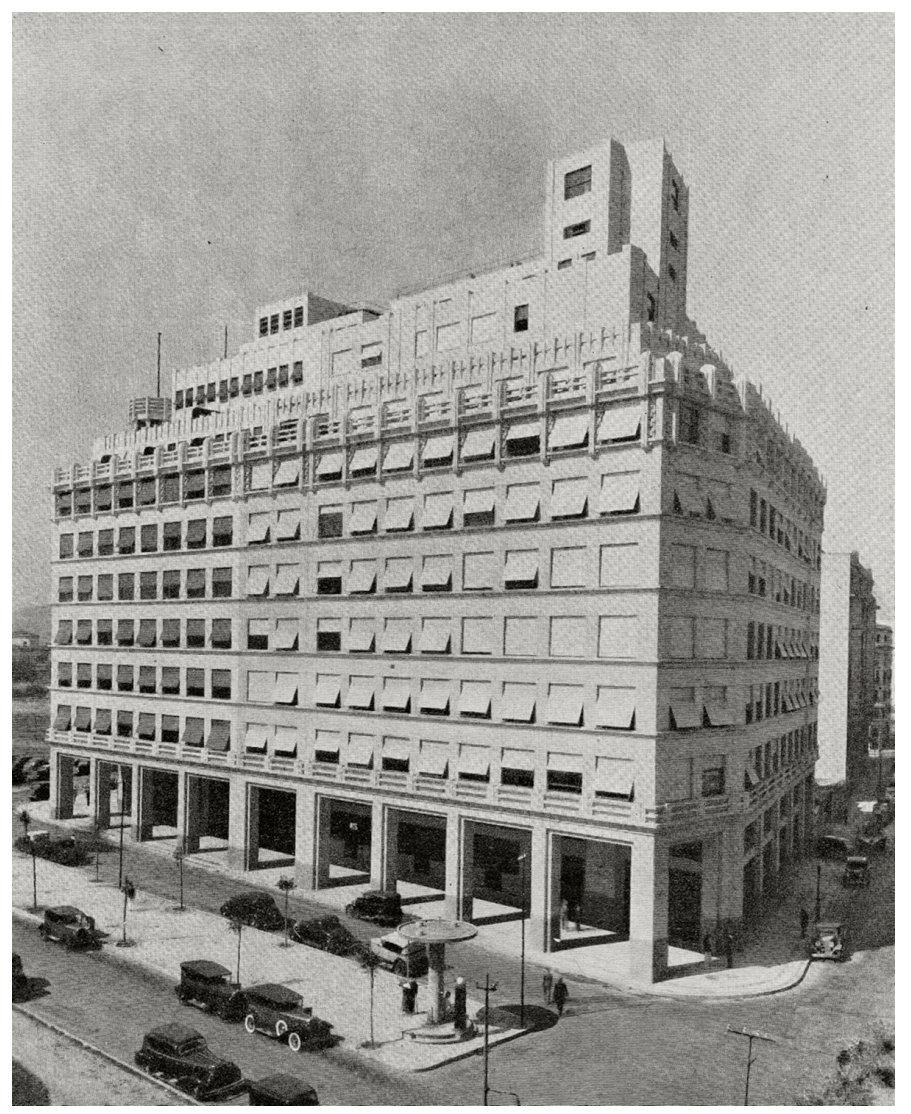

Figura 6: Edifícios Castelo, Nilomex e Raldia. Fonte: ARQUITETURA E URBANISMO, 1937, n. 2, p. 76

Figura 7: Edifícios Castelo, Nilomex e Raldia. Fonte: ARQUITETURA E URBANISMO, 1937, n. 2, p. 77

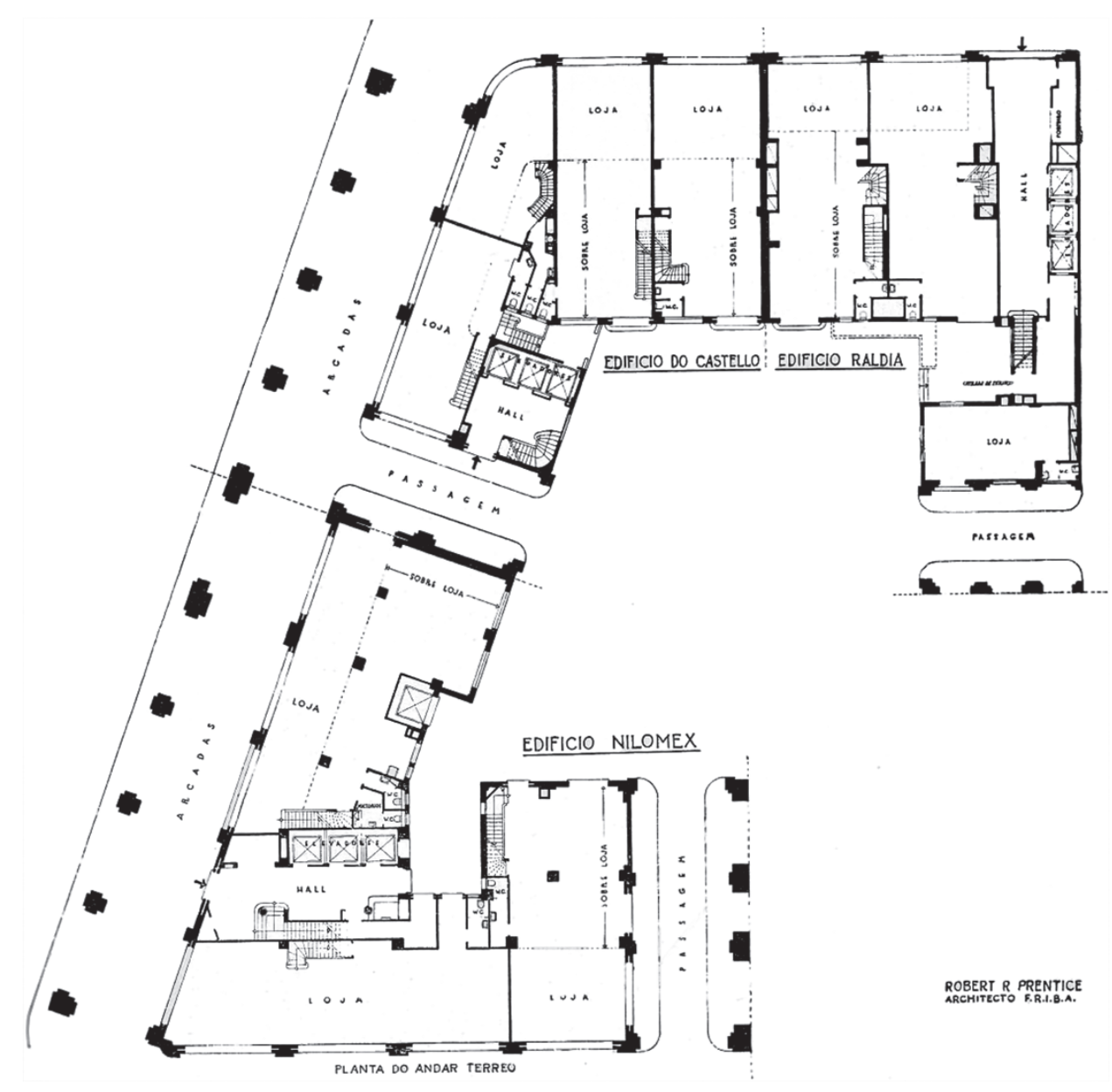


11 Termo conforme utilizado na época pela revista.
Figura 8: Edifício J. Pimentel Duarte. Fonte: ARQUITETURA E URBANISMO, 1936, n. 3, p. 132.
Projeto de Paulo Pires e Paulo Santos, o Edifício J. Pimentel Duarte, construído em 1936, hoje demolido, impressiona pela proposta de edifício residencial verticalizado construído na orla carioca ainda dominada por edificações baixas. O preconceito da época contra esse tipo de moradia, que era associada a cortiços e conjuntos habitacionais, ressalta a ousadia da empreitada. Efeito de contraste similar pode ser imaginado no caso dos edifícios residenciais Columbus e Guarani, projetados por Rino Levi e construídos em São Paulo também nos anos 1930.

Com dez andares, solto no lote, o edifício foi projetado com terraço na laje de cobertura, play-ground ${ }^{11}$, garagem, "um amplo vestíbulo, a cuja entrada uma grande 'marquize' em cimento armado abriga os automóveis em dias de chuva" (ARQUITETURA E URBANISMO, n. 3, set./out., 1936, p. 132), além de uma "aparelhagem de refrigeração central, com unidades refrigerantes (geladeiras) em cada apartamento" (ARQUITETURA E URBANISMO, n. 3, set./out., 1936, p. 137).

Apesar de demonstrar estar atualizado e reconhecer a qualidade das soluções de projeto, o editorial não hesita em demonstrar certo desapreço pelo arranha-céu residencial, mesmo considerando que um dos autores, Paulo Pires, fazia parte do conselho técnico da revista:

Construido em centro de terreno, sem aquelas paredes nuas de uso tão frequente, apezar de seu aspecto desagradavel, esse imovel se impõe pelo equilíbrio de suas massas, que, externamente, talvez seja a sua maior qualidade [...] Sua planta foi resolvida sem areas internas, desse modo, a ventilação e a iluminação de todos os compartimentos se torna perfeita. Essa disposição, evidentemente ideal, tem sido pouco procurada; entretanto, só se deve recorrer a areas internas fechadas na impossibilidade de evita-las por completo. Esta tese acaba de ser brilhantemente sustentada em um artigo publicado o ano passado na revista mundial L'ARCHITECTURE D'AUJOURD'HUI. (ARQUITETURA E URBANISMO, n. 3, set./out., 1936, p. 132)

A distribuição dos ambientes nas plantas, a redução funcionalista do núcleo de serviços e a racionalização das circulações no projeto de Pires e Santos, mostram um protótipo do que viria a ser a banalização do edifício residencial verticalizado nas cidades brasileiras da segunda metade do século 20.

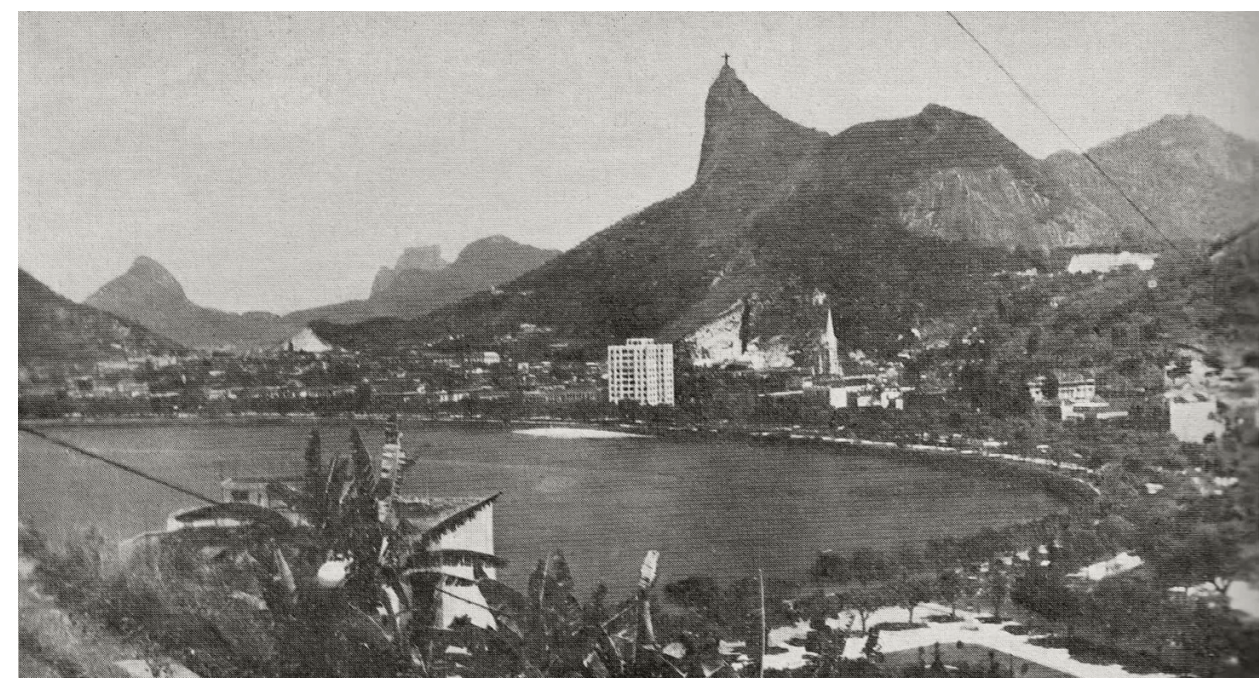




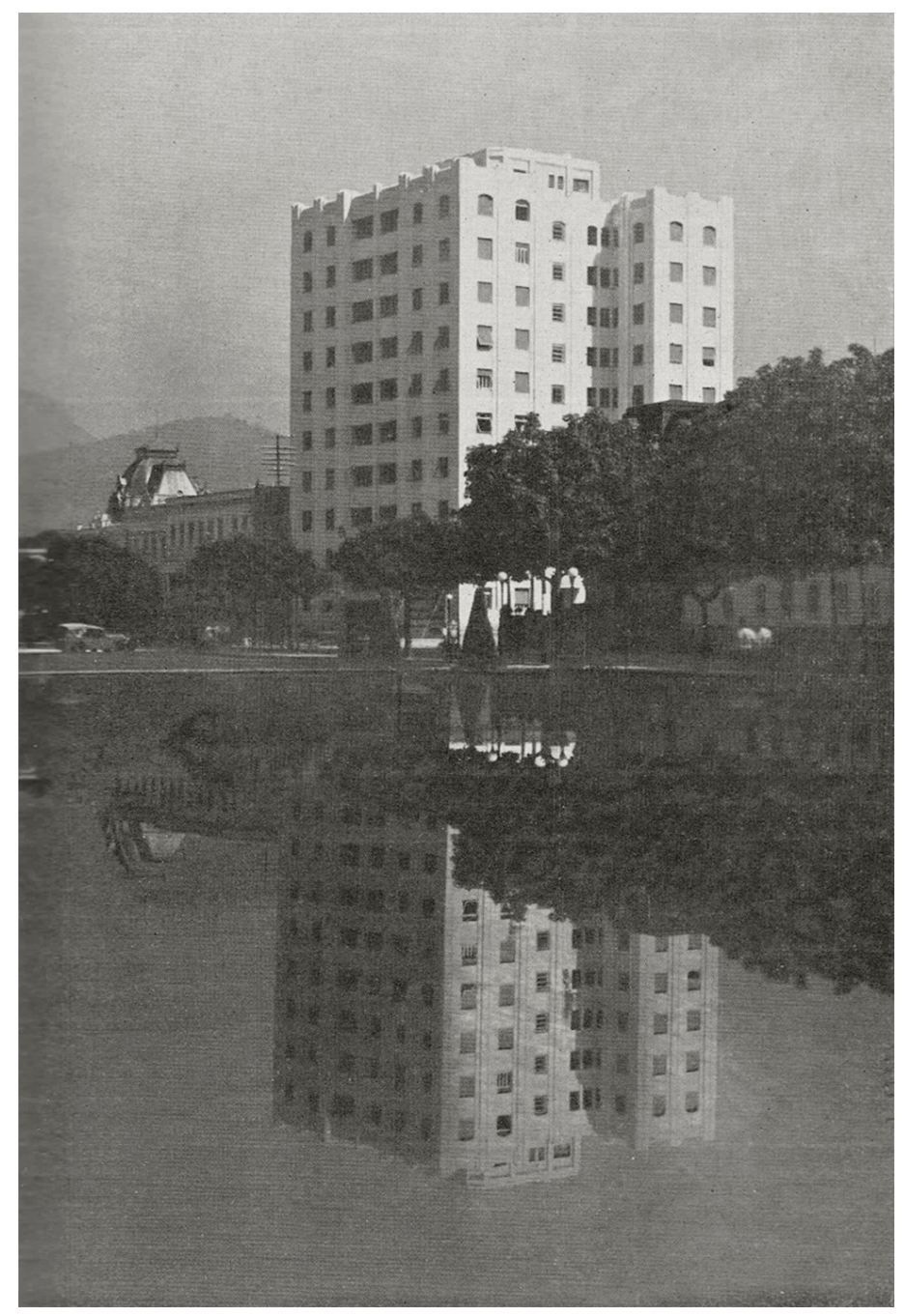

Figura 9: Edifício J. Pimentel Duarte. Fonte: ARQUITETURA E URBANISMO, 1936, n. 3, p. 131.

Figura 10: Edifício J. Pimentel Duarte. Fonte: ARQUITETURA E URBANISMO, 1936, n. 3, p. 134.

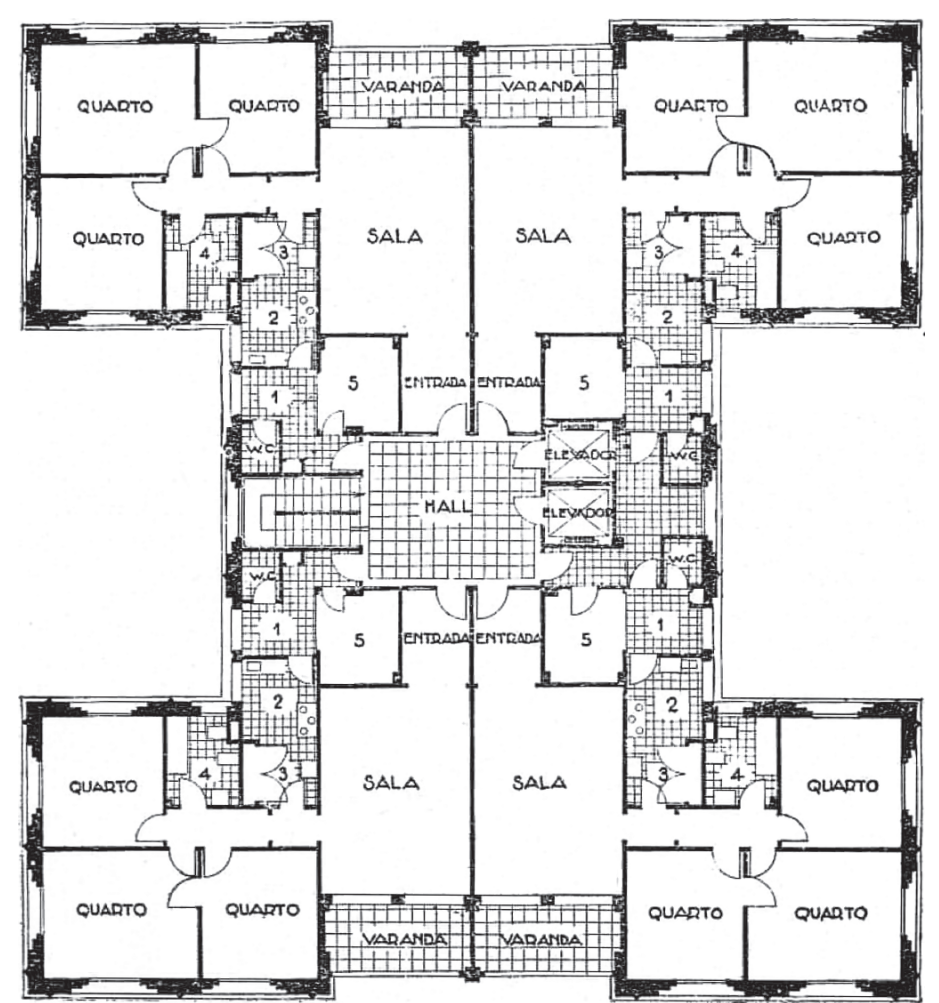


Figura 11: Edifício Raposo Lopes. Fonte: ARQUITETURA E URBANISMO, 1938, n. 4, p. 192.
O Edifício Raposo Lopes, publicado em 1938, projeto de Adhemar Marinho, parceiro de Álvaro Vital Brazil no projeto do pioneiro Edifício Esther em São Paulo (SEGAWA, 1999, p. 87), ocupa um terreno privilegiado no alto do morro de Santa Teresa no Rio de Janeiro. Tão disruptivo quanto o Ed. Pimentel Duarte em termos de infraestrutura, equipamentos e planta, o edifício se diferencia deste último pela proposta isenta de ornamentos e pelos grandes balcões que se fazem de varanda para os dormitórios.

Com relação ao estudo da evolução do projeto e do uso do espaço residencial, é curioso notar que é quase regra ver nos projetos residenciais publicados pela revista o espaço da varanda vinculado ao dormitório. Tal observação atenta para como essa relação foi se alterando ao longo do tempo, quando o ambiente a ser estendido pela varanda passa a ser a sala de estar, o que incluí as casas modernistas com as áreas de estar intimistas e voltadas para pátios e jardins, já no caso da habitação vertical essa tendência de valorizar o espaço de transição entre o público e o privado atinge o seu extremo nas atuais varandas gourmet. Talvez o único caso encontrado na revista, entre residências de dois pavimentos e edifícios residenciais em altura, onde a varanda é conjugada com a sala de estar ao invés do dormitório é o Ed. Pimentel Duarte comentado anteriormente. No caso do Raposo Lopes o espaço estendido pela generosa varanda segue o costume da época, porém, há uma porta conectando timidamente a sala à varanda.

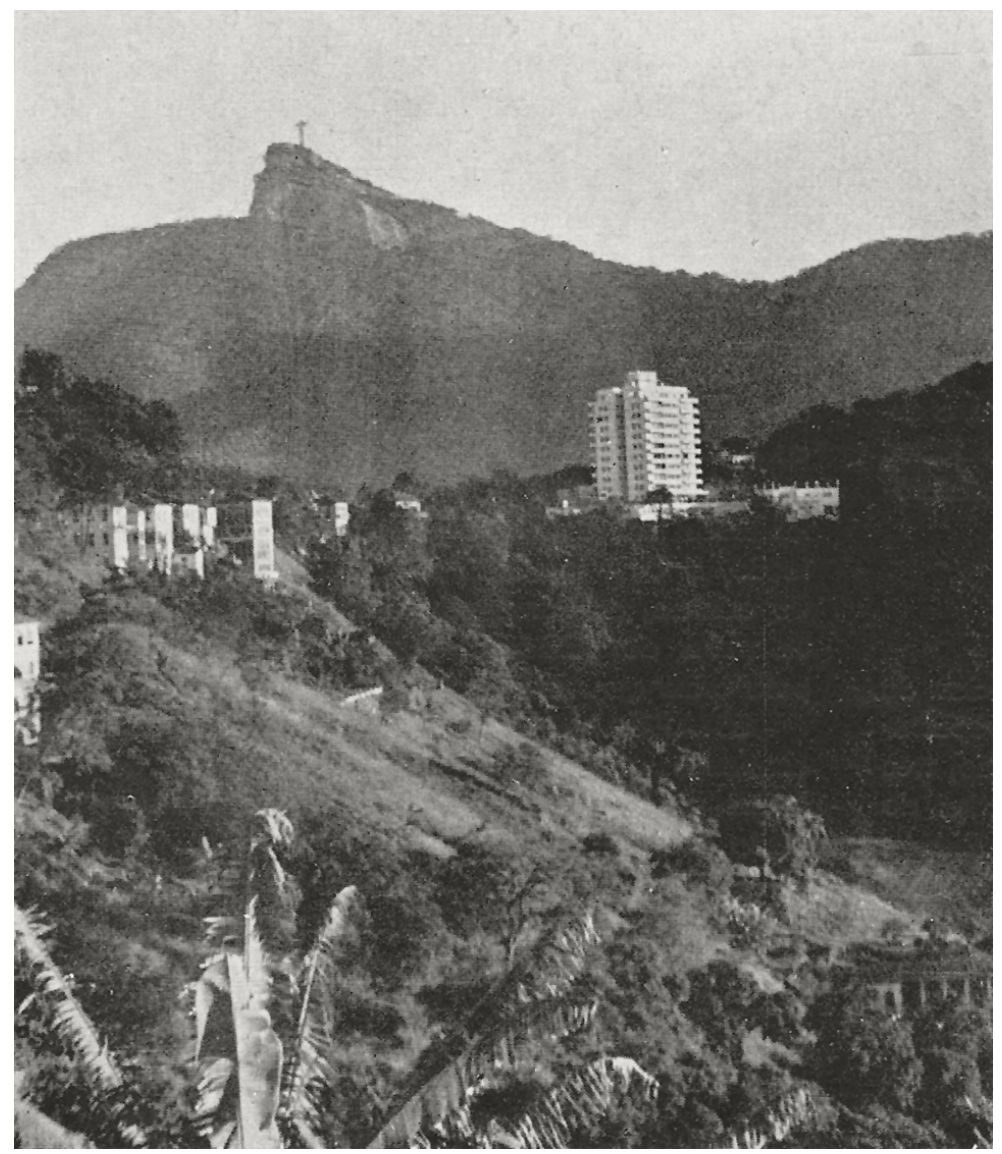



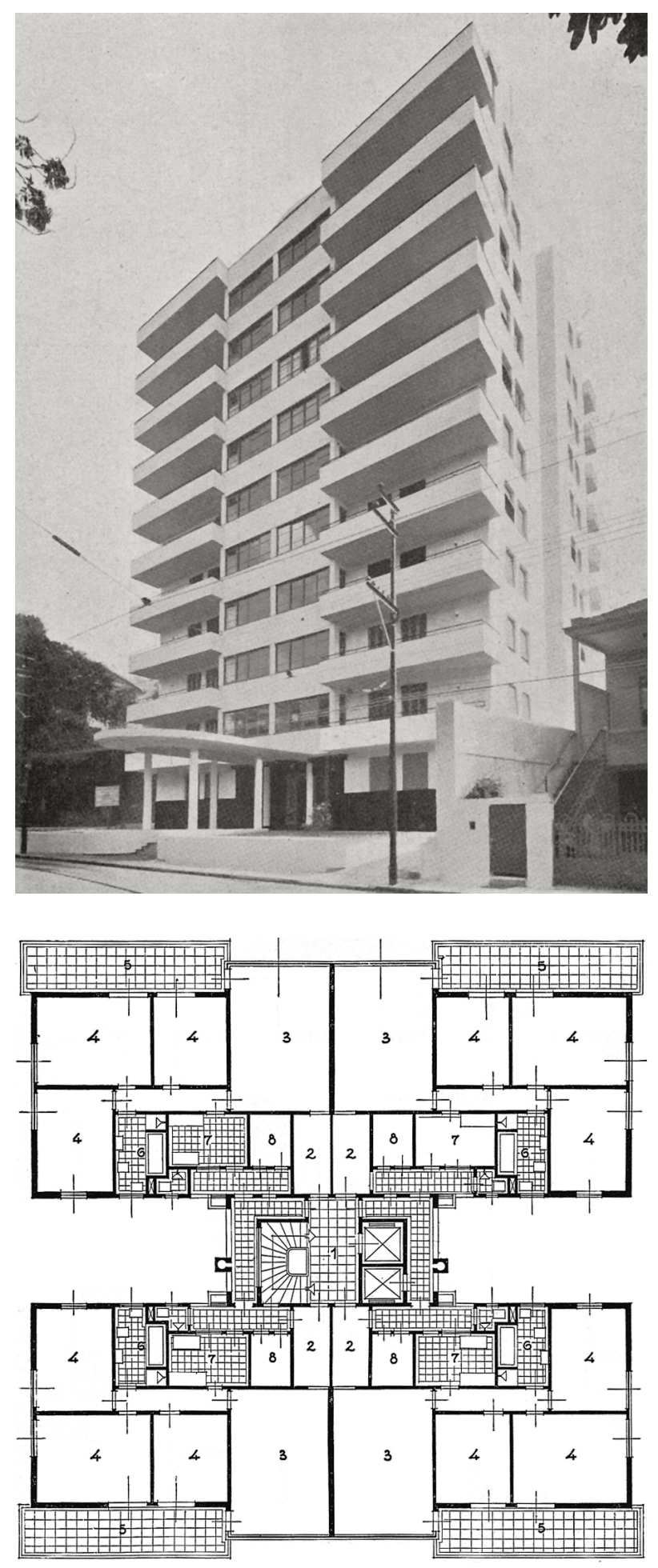

Figura 12: Edifício Raposo Lopes. Fonte: ARQUITETURA E URBANISMO, 1938, n. 4, p. 193.

Figura 13: Edifício Raposo Lopes. Fonte: ARQUITETURA E URBANISMO, 1938, n. 4, p. 191.
Uma outra característica que torna o Raposo Lopes incomum é a presença de uma grande piscina voltada para prática esportiva que se projeta sobre a encosta do morro apoiada em uma grelha de concreto. Construída posteriormente, não se sabe quando, fotos antigas e relatos de moradores encontrados na internet, sugerem que a piscina e o salão de baile construído sob a mesma não foram construídos muito tempo após a inauguração do edifício em 1938². 
12 Não há imagens da piscina publicadas em Arquitetura e Urbanismo, porém, existem registros e depoimentos na internet que ressaltam o impacto do equipamento esportivo e de lazer na vizinhança. Cf. PERMANÊNCIAS E DESTRUIÇÕES. Disponível em: <https://www.youtube.com/ channel/UCoJypjK4uYEyhzUwglf8Uhg >. Acesso em: 25 out. 2018 e AMAST - Associação de Moradores e Amigos de Santa Teresa. Disponível em: <https:// www. facebook.com/amast. santateresa/?tn-str $=k * F>$. Acesso em: 25 out. 2018 .

130 idealizador da revista Cipriano Lemos era membro próximo dos dirigentes da Igreja Positivista do Brasil, não se sabe ao certo se havia algum parentesco entre ele e Miguel Lemos, o fundador da igreja e co-autor da atual bandeira brasileira, mas o seu alto status social pode ser inferido pelo fato do mesmo ter sido amigo e cunhado do também positivista Marechal Cândido Rondon (ARQUITETURA E URBANISMO, n. 5, p. 651, set./out., 1939).

14 Projeto do arquiteto Léon d'Escoffier (ARQUITETURA E URBANISMO, n. 2, p. 430, mar./ abr., 1939).
De um ponto de vista global, a análise da revista revela um ambiente bacharelesco voltado para a produção do profissional liberal, de preferência sócio do IAB, focado no mercado privado, que vincula fortemente a obra ao autor. O lugar-comum dos artigos alardeia, de maneira elitista para os olhos de hoje, o arquiteto como o profissional focado no projeto como atividade superior por ser considerada exclusivamente intelectual, que na defesa da profissão recém-regulamentada, insiste em fazer um contraponto ostensivo e de certa forma ressentido entre o trabalho intelectual do arquiteto formado e a atividade parcialmente "contaminada" pelo trabalho manual dos práticos e construtores não diplomados, que também se diziam arquitetos e dominavam o mercado da construção na época.

Apesar da tendência de manter o foco na arquitetura como belas artes sem dispensar a contribuição da cultura técnica centrada na figura do engenheiro, como não poderia deixar de ser em um ambiente impregnado pelo positivismo ${ }^{13}$, Arquitetura e Urbanismo faz jus ao seu nome ao considerar, mesmo que de maneira secundária, o urbanismo entendido no seu sentido de obra voltada para a coletividade. Pode-se considerar seguramente que o periódico não deu as costas para as obras públicas da época, porém, na maioria das análises, a revista não se posicionou acerca do valor de interesse social contido na divulgação desses empreendimentos, o que mostra um certo descompasso em relação àquela que estava se tornando uma das linhas mestras da arquitetura moderna de então.

Arquitetura e Urbanismo publicou alguns projetos e obras públicas de vulto, como o concurso do Aeroporto Santos Dumont (1937), cujas propostas mostram uma modernidade que extrapola o grupo ligado a Lucio Costa; a Estação de Hidroaviões do mesmo aeroporto (1938) e a Ponte Brasil ${ }^{14}$ ligando o Rio de Janeiro a Niterói (1939), comentada em artigo de Attílio Corrêa Lima; o projeto do edifício do Ministério da Educação e Saúde (1939); o Hospital das Clínicas em São Paulo (1939), entre outras. No entanto, como era de se esperar considerando a cultura arquitetônica da época, o viés analítico das matérias tende mais para a questão da obra como objeto arquitetônico e técnico do que para sua relação com a cidade ou mesmo como objeto histórico.

Ao buscar outros projetos que seguem essa linha de projetos públicos inseridos no quadro de modernização varguista, o que incluí a abordagem de uma produção de arquitetura moderna que está fora dos manuais, considerou-se importante explorar o caso da Estação de Hidroaviões de Salvador. Iniciativa do Departamento de Aeronáutica Civil do Estado Novo, o equipamento de infraestrutura aeroportuária foi projetado por Ricardo Antunes, segundo e último diretor de Arquitetura e Urbanismo. Interessado e especialista em urbanismo, Antunes mostra uma trajetória paralela à de Attílio Corrêa Lima, de quem foi colega de turma no curso da ENBA, projetou para o estado as estações de hidroaviões de Salvador e Vitória, enquanto que seu colega consagrado pela historiografia projetou a hidrobase da capital federal.

O edifício ainda existente, muito degradado e com uso distinto mostra uma adesão formal e espacial quase que irrestrita ao modelo das vanguardas aplicado a um programa plenamente moderno. É interessante ressaltar que o uso de hidroaviões, entre outros veículos como os Zeppelins alemães, na aviação civil e comercial de larga escala é uma característica muito peculiar dos anos 1930. Cláudio Pereira (2003) observa que as primeiras rotas aéreas internacionais eram operadas por hidroaviões e que o Departamento de Aviação, acreditando ser essa a tendência, investiu primeiro 
Figura 14: Estação de Hidroaviões de Salvador. Fonte: ARQUITETURA E URBANISMO, 1939, n. 5, p. 619

15 Termo utilizado na época de maneira pejorativa, como ilustra o artigo desfavorável ao modernismo publicado pelo jornalista português Julio Dantas, intitulado "Bolchevismo Arquitetônico" (ARQUITETURA E URBANISMO, n. 4, jul./ago., 1938).

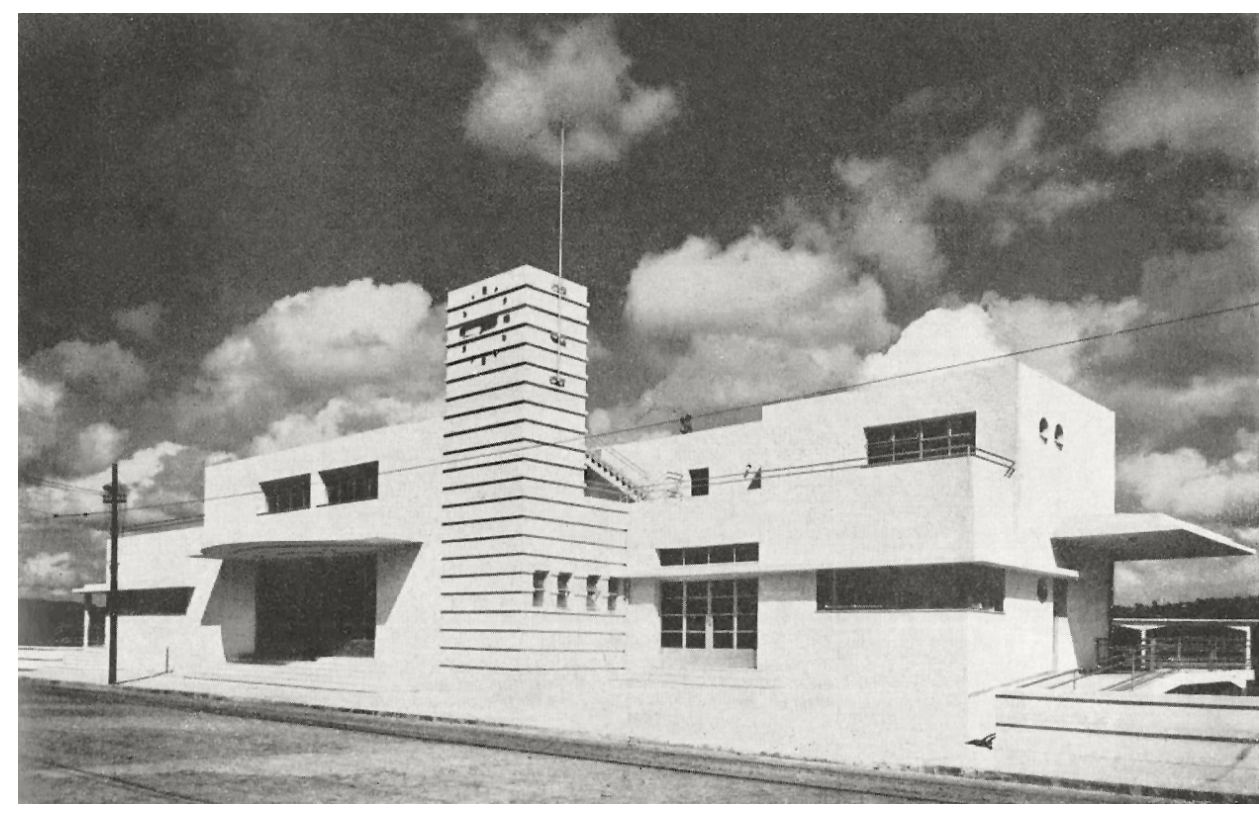

nos concursos e na construção de estações para hidroaviões, tendência que não se confirmou, pois, após a segunda guerra o modelo que se firmou foi o dos aeroportos, ficando as hidrobases abandonadas ou sendo utilizadas por pequenos aviões particulares.

No que concerne à arquitetura, nota-se que a inserção desajeitada da torre atarracada com mastro e relógio de influência déco, diante da predominância das linhas horizontais do restante do edifício e do meio circundante, sugere uma concessão conservadora do arquiteto a um público abastado e composto por autoridades que provavelmente não se sentiriam representadas diante da nudez democratizante e do internacionalismo "bolchevista" 15 do restante do edifício.

\section{Conclusão}

A análise da revista publicada pelo IAB no final dos anos 1930 observa uma outra face da história da arquitetura moderna brasileira que, sem negar o impacto das conferências de Le Corbusier, fato largamente documentado nas páginas do periódico, mostra como são diversas e particulares as respostas dos arquitetos diante dos desafios do ambiente e da mentalidade moderna. Além disso o estudo desse periódico deixa claro o quanto esses profissionais liberais, no sentido estrito do termo, não se incluíam como parte de um "movimento moderno" que prometia a transformação social através da arquitetura, por isso seus interesses, suas influências e suas obras se mostram tão díspares.

Assumindo-se como um reforço à tendência de alargamento e revisão historiográfica iniciada no Brasil nos anos 1980, este estudo pretende se inserir como fragmento interpretativo para a reconstituição de narrativas maiores, mais inclusivas e inéditas que superem o insistente e ainda presente campo de influência dos "relatos canônicos e suas balizas" (TRAJANO FILHO, 2013, p. 3). Como este artigo é parte de um estudo maior que se encontra em desenvolvimento, concluímos provisoriamente, que a arquitetura moderna brasileira oriunda daquilo que se convencionou chamar de "escola carioca" 
é menos especial do que a historiografia se esforçou e tem se esforçado para nos fazer acreditar e que a sua proximidade com essa arquitetura dos anos 1930 "de fora do circuito das vanguardas", com a qual foram construídas as primeiras metrópoles do Brasil é muito maior do que nos faria supor, o que sugere que há mais continuidade do que ruptura nesse processo.

\section{Referências bibliográficas}

ACRÓPOLE. São Paulo: Max Gruenwald \& Cia. n. 1, maio, 1938.

INSTITUTO BRASILEIRO DE GEOGRAFIA E ESTATÍSTICA. Censo Demográfico 1872, 1890 1900, 1920, 1940, 1950, 1960, 1970, 1980, 1991, 2000 e 2010. Disponível em: https:// censo2010.ibge.gov.br/sinopse/index.php?dados=6\&uf=00. Acesso em: 03 nov. 2018.

AMAST Associação de Moradores e Amigos de Santa Teresa. Disponível em: <https://www. facebook.com/amast.santateresa/?tn-str=k*F>. Acesso em: 25 out. 2018.

ANELLI, Renato. Arquitetura de cinema em São Paulo. O cinema e a construção do moderno. In: GUERRA, Abilio (Org.) Textos fundamentais sobre a história da arquitetura moderna brasileira. São Paulo: Romano Guerra, 2010. v.1.

ARQUITETURA E URBANISMO. Rio de Janeiro: IAB, 1936-1942. Bimensal.

FAUSTO, Boris. História do Brasil. São Paulo: Edusp, 1995.

GOLDHAGEN, Sarah Williams. Algo de qué hablar: modernismo, discurso, estilo. Tradução e prefácio de Juan Luis Rodríguez Gómez. Bitácora Urbano Territorial, Bogotá, n. 12, p. 11 42, jan./jun., 2008. Disponível em: <https://revistas.unal.edu.co/index.php/bitacora/article/ view/18607>. Acesso em: 08 set. 2018.

MARTINS, Carlos Alberto Ferreira. Arquitetura e Estado no Brasil. Elementos para uma análise da constituição do discurso moderno no Brasil. A obra de Lucio Costa 1924-52. Dissertação (Mestrado em História Social) - Faculdade de Filosofia, Letras e Ciências Humanas, Universidade de São Paulo, São Paulo, 1988.

MEYER, Regina Maria Prosperi. São Paulo Metrópole. São Paulo: Edusp, 2004

NERY, Juliana Cardoso. Falas e ecos na formação da arquitetura moderna no Brasil. Tese (Doutorado) - Universidade Federal da Bahia, Faculdade de Arquitetura, Salvador, 2013.

PEREIRA, Cláudio Calovi. O pórtico clássico como terminal aéreo: os projetos dos irmãos Roberto para o aeroporto Santos Dumont. Arqtexto, Porto Alegre, n. 3-4, p. 122-135, 2003. Disponível em: <https://www.ufrgs.br/propar/publicacoes/ARQtextos/PDFs_revista_3-4/13_Cl\%C3\%A1udio\%20Calovi\%20Pereira.pdf>. Acesso em: 05 out. 2018.

PERMANÊNCIAS E DESTRUIÇÕES. Disponível em: <https://www.youtube.com/channel/UCoJypjK4uYEyhzUwglf8Uhg>. Acesso em: 25 out. 2018.

PINHEIRO, Cláudia (org.). IAB: oitenta anos no Rio de Janeiro. Rio de Janeiro: IAB/RJ, 2001.

RABELO, Clévio. Arquitetos na cidade: espaços profissionais em expansão [Rio de Janeiro, 192535]. 2011. Tese (Doutorado em História e Fundamentos da Arquitetura e do Urbanismo) - Faculdade de Arquitetura e Urbanismo, Universidade de São Paulo, São Paulo, 2011.

ROITER, Márcio. Rio de Janeiro art déco. Rio de Janeiro: Casa da Palavra, 2011.

SEGAWA, Hugo Massaki. Arquiteturas no Brasil 1900-1990. São Paulo: EDUSP, 1999.

TRAJANO FILHO, Francisco Sales. Do que falamos quando falamos de arquitetura moderna no Brasil. In: $3^{\circ}$ Seminário Ibero-Americano Arquitetura e Documentação, 2013, Belo Horizonte/MG. $3^{\circ}$ Seminário Ibero-Americano Arquitetura e Documentação: anais e caderno de resumos. Belo Horizonte/MG: UFMG, 2013. 